\title{
Geração e aplicação de novos atributos sísmicos de dados 2D aquisitados para a exploração de Óleo e Gás e reprocessados para exploração de Sais de Potássio na Sub-bacia de Sergipe, Brasil
}

\author{
${ }^{*}$ R.M.D. Fávera ${ }^{1}$, C. Contreras ${ }^{1}$, P. Cabrera ${ }^{2}$, C. Aristizábal ${ }^{1}$, J. Silva ${ }^{2}$ \\ (1. UFRJ/COPPE/LAMCE/Lab2M - Multidisciplinary Modeling Laboratory \& 2. PETREC - Petroleum Research and \\ Technology)
}

Copyright 2016, SBGf - Sociedade Brasileira de Geofísica

Este texto foi preparado para a apresentação no VII Simpósio Brasileiro de Geofísica, Ouro Preto, 25 a 27 de outubro de 2016. Seu conteúdo foi revisado pelo Comite Técnico do VII SimBGf, mas não necessariamente representa a opinião da SBGf ou de seus associados. É proibida a reprodução total ou parcial deste material para propósitos comerciais sem prévia autorização da SBGf.

\begin{abstract}
This study presents an exploration geophysics workflow of potassium salts, seeking to improve the identification of thinning bedding salt deposits, by using well profiles and 2D seismic network data, only. The initial procedure was the increase of the frequency band and the use of directional filters on seismic data, in order to highlight the structures and layers. Hence, the development of prestack and post-stack sensitive attributes to the salt presence, and finally, the integrated interpretation of seismic and well data. Those methods' application results in the identification of promising zones that will permit focusing a new acquisition data necessary to accurate the resolution and take a better decision before drilling.
\end{abstract}

\section{Introdução}

O potássio é um elemento abundante na crosta terrestre, pois compõe muitos minerais constituintes das rochas, como o feldspato potássico e a muscovita. Por mais que esses minerais contenham porcentagem entre 10 e $20 \%$ de $\mathrm{K}_{2} \mathrm{O}$ equivalente, não correspondem a boas fontes de potássio, pois são pouco solúveis ou insolúveis e suas estruturas não são facilmente rompidas por meios artificiais. O potássio também não ocorre na natureza em sua forma elementar. Desta maneira, a nível industrial, as principais fontes econômicas de sais de potássio ocorrem em depósitos evaporíticos, onde é possível obter os minerais silvita, que pode conter até $53 \%$ de $\mathrm{K}_{2} \mathrm{O}$, e a carnalita, com teor que pode chegar a $15 \%$ de $\mathrm{K}_{2} \mathrm{O}$, assim como a mistura silvita e halita, denominada de silvinita $(\mathrm{KCl}+\mathrm{NaCl})$, constituindo-se no principal minério de potássio (Oliveira, 2008; Nascimento \& Miranda, 2015). A maior utilização do potássio é para fertilizantes, sendo o restante consumido pela indústria química, para auxiliar na manufatura de vidros especiais, sabões, detergentes, assim como na perfuração de poços petrolíferos.

As principais reservas de sais de potássio no Brasil estão localizadas nos estados de Amazonas e Sergipe. Na subBacia de Sergipe, foco do presente estudo, as regiões de Taquari/Vassouras e Santa Rosa de Lima apresentam reservas oficiais de silvinita totalizam 478,0 milhões de toneladas, com teor médio de $9,7 \%$ de $\mathrm{K} 2 \mathrm{O}$ equivalente (Oliveira, 2014).
Para a prospecção de sais de potássio, são necessários amplos conhecimentos da geologia regional e local, da evolução tectono-sedimentar e paleogeografia da área. Alia-se também toda a informação possível de dados já adquiridos na área, a fim de caracterizar os depósitos de sais de potássio tanto lateralmente, quanto em profundidade.

No mundo, muitos métodos geofísicos são aplicados para prospecção de sais de potássio, como levantamentos aéreos e terrestres de gama espectrometria, log de poço, levantamento sísmico, métodos potenciais, eletromagnetometria, sensoriamento remoto, e outros. Os maiores países produtores de sais de potássio possuem base de dados grande e atualizada disponível para consulta e disponibilizada publicamente.

No Brasil, a maioria dos dados públicos, especialmente dados de sísmica e de poços, é antiga e foi aquisitada para a indústria de óleo e gás. Consequentemente, os depósitos de sais de potássio não são bem conhecidos e os processos de detecção dos mesmos ainda são muito limitados. Contudo, existem diferentes fontes de informação que se forem bem integrados, reprocessados e reinterpretados, podem ser de grande valia para geração de novos produtos e resultados.

\section{Metodologia/ Problema Investigado}

Para alcançar a proposta principal do trabalho, foram aplicadas certas técnicas habitualmente utilizadas para processamento de dados para métodos potenciais. Com isso, foi possível destacar estruturas, contatos litológicos e continuidade lateral das unidades evaporíticas. Nesse estudo de caso, contamos com 17 dados 2D em SEG-Y e 14 poços com perfis compostos distribuídos próximo a linha de costa da sub-Bacia de Sergipe (Figura 1).

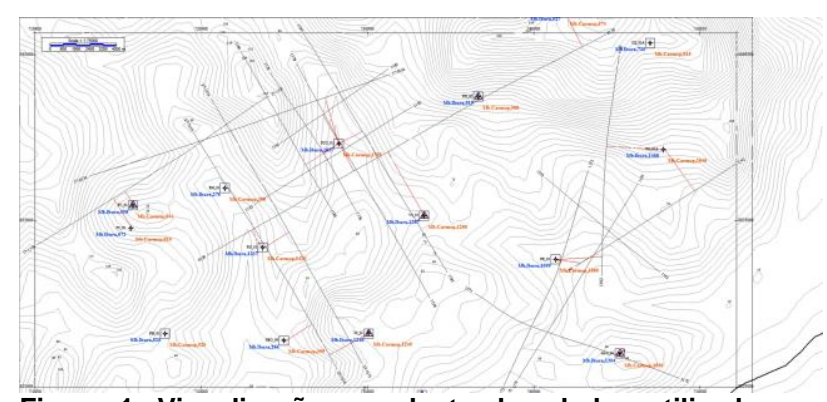

Figura 1: Visualização em planta dos dados utilizados no trabalho.

Os dados de poços foram carregados e calculados os pseudo-registros, a partir dos dados de cada poço, obtendo assim, curvas de velocidade e resistividade, 
além de densidade e pseudo-sônico. Posteriormente, a partir de uma análise de atributos usando Gamma-ray confrontado com o registro sônico/pseudo-sônico ou de resistividade, foi calculada uma zona de frequências (GRHigh e GR-Low). Também foram calculadas curvas de pseudo-resistividade. Assim, obteve-se como resultado a calibração dos poços e identificação dos registros que detectam grande nível produtor de sal (Figura 2).

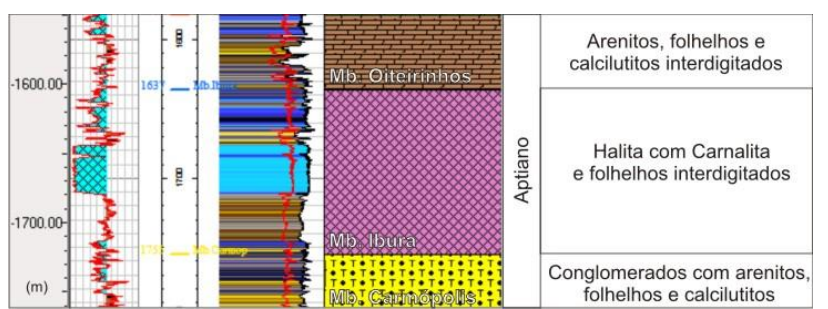

Figura 2: Cross-plotting (Gamma-ray - Densidade) para mostrar uma seção espessa do Mb. Ibura (quadro rosa). É interessante notar o traço azul escuro (Carnalita) dentro da seção azul clara (Halita) no perfil.

A amarração das seções sísmicas aos poços por meio dos registros e pseudo-registros foi realizada levando em conta os perfis de velocidade de cada uma das linhas sísmicas, ajustando os registros elétricos aos dados de sísmica mediante a criação de um sismograma sintético, baseado no cálculo de wavelets dos poços mais profundos.

Os atributos sísmicos são basicamente classificados em duas categorias: Atributos físicos e geométricos. Os físicos são aqueles diretamente relacionados com propagação de onda, litologia e outros parâmetros. Os geométricos se relacionam com dip, azimute e descontinuidade das camadas. Desta forma, os atributos THDPR e ESR foram desenvolvidos internamente na PETREC para atender à demanda da indústria de exploração mineral.

\section{- THDPR: Total Horizontal Gradient with Phase Rotation}

O índice espacial de mudança do sinal sísmico na derivada horizontal (na direção X) pode contribuir para realçar as estruturas geológicas. Usamos derivada vertical (Z) para detectar contatos litológicos verticais. A derivada total horizontal pode ser descrita como a raiz quadrada da soma das derivadas horizontais $\mathrm{x}$ e $\mathrm{y}$ ao quadrado. Para isso, é comumente utilizado o filtro de detecção de bordas (Cooper \& Cowan, 2008). Nós rotacionamos a derivada total em 90 graus para melhorar a visualização de contatos laterais e verticais nos dados sísmicos.

\section{- ESR: Envoltory of Seismic Reflection}

Nabighian (1972) desenvolveu o conceito de sinal analítico de anomalias magnéticas. Roest, Verhoef, e Pilkington (1992) demostraram que a amplitude do sinal analítico pode ser deduzida a partir dos gradientes ortogonais do campo magnético total. O gradiente vertical é projetado com o conteúdo do gradiente da frequência do sinal sísmico. Este atributo é capaz de evidenciar tanto as falhas geológicas, quanto os contatos litológicos.

\section{Resultados}

Após a calibração dos dados de poços e criação dos atributos sísmicos, foi possível realizar a interpretação sísmoestratigráfica com grande precisão. Com a calibração dos dados de poços, foi possível visualizar a linha sísmica com o topo das formações/ membros, curvas de Raio Gama (GR) e Densidade (Den_from_Sonic) já plotadas (Figura 3).

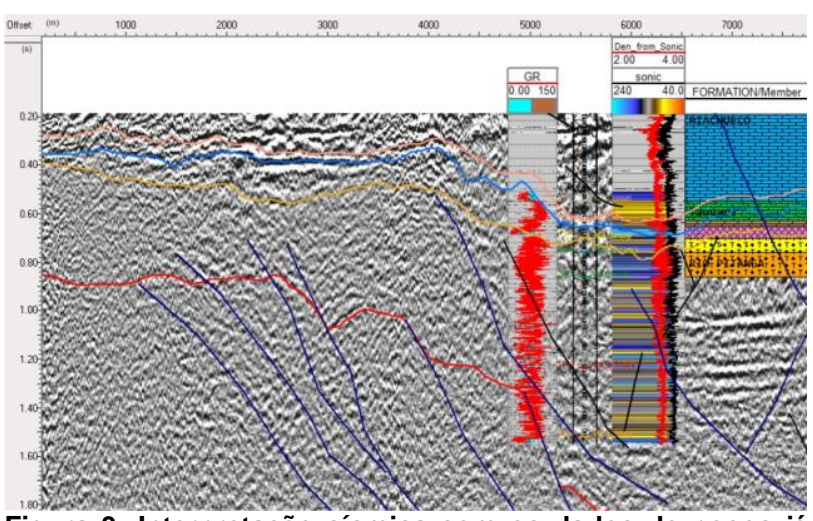

Figura 3: Interpretação sísmica com os dados de poços já calibrados e dado sísmico sem atributo aplicado.

Com a aplicação do atributo THDPR (Figura 4), os refletores sísmicos apresentaram grande continuidade lateral e com o atributo ESR (Figura 5) as estruturas geológicas ficaram bem marcadas. Foi possível assim, realizar novamente a interpretação das linhas sísmicas de uma forma mais precisa, evitando afinamentos e espessamentos equivocados poderiam induzir às investigações em locais inapropriados (Figura 6).

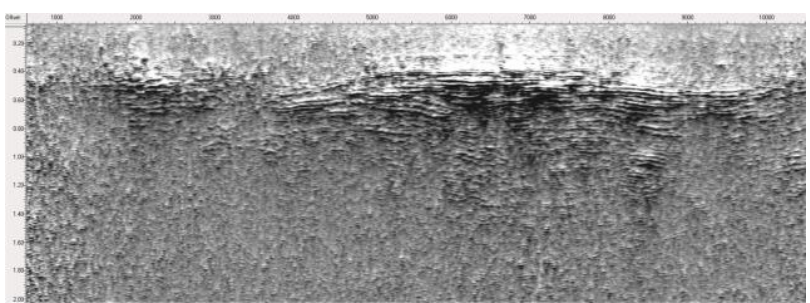

Figura 4: Dado sísmico com o atributo THDPR aplicado.

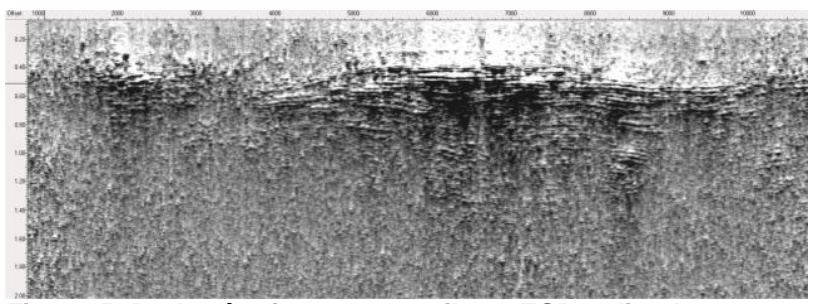

Figura 5: Dado sísmico com o atributo ESR aplicado. 


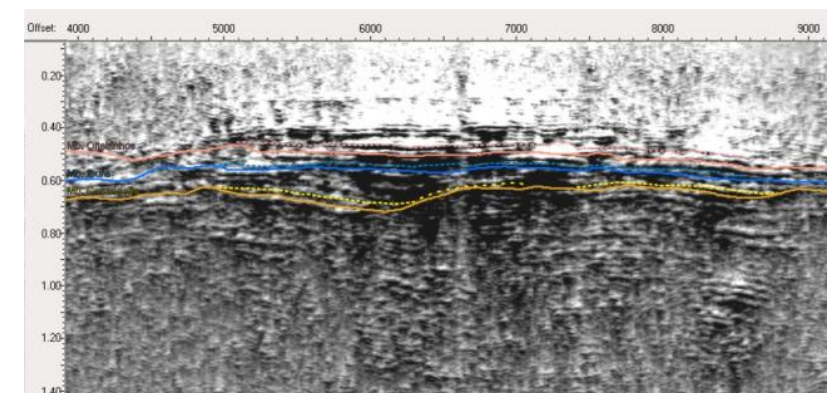

Figura 6: Reinterpretação do dado sísmico após a aplicação do atributo THDPR. As linhas contínuas representam a interpretação exportada da linha original sem tratamento. A linha pontilhada refere-se à nova interpretação.

Assim, após o entendimento estrutural prévio da bacia, localizando os altos e baixos estruturais e analisando a relação desse contexto com a espessura dos níveis evaporíticos, além da calibração dos poços e aplicação dos atributos, foi possível localizar as maiores espessuras desses corpos salinos (Figura 7).

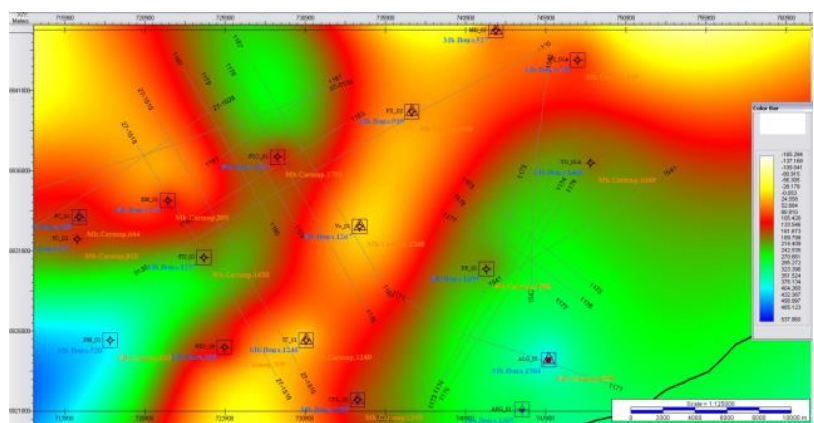

Figura 7: Mapa de espessura do Mb. Ibura (evaporitos). A cor azul representa a maior espessura da camada, enquanto a cor amarela mostra a menor espessura. Profundidade em metros.

\section{Discussão e Conclusões}

A metodologia apresentada no trabalho é uma forma segura de diminuir o investimento inicial na exploração de sais de potássio. Com ela, é possível obter alto nível de certeza na localização dos níveis mais espessos do alvo exploratório para direcionar um novo levantamento do mesmo. Para este novo levantamento, é necessário que haja uma aquisição sísmica $3 \mathrm{D}$ na área do alvo escolhido, mesmo que seja uma área reduzida, além de um ou dois poços perfilados e com checkshots. Assim será possível realizar a cubagem do possível minério.

\section{Agradecimentos}

Os autores agradecem à UFRJ / COPPE / LAMCE / Lab2M - Multidisciplinary Modeling Laboratory e PETREC - Petroleum Research and Technology pela oportunidade de realizar o manuscrito.

\section{Referências}

Cooper, G. R., \& Cowan, D. R., 2008. Edge enhancement of potential-field data using normalized statistics. Geophysics((3): H1-H4), 73.

Nabighian, M. N., 1972. The analytic signal of two-dimensional magnetic bodies with polygonal cross-section: its properties and use for automated anomaly interpretation. Geophysics, 37 (3), 507-517.

Nascimento, R. L., \& Miranda, L. A., 2015. Exploração de Potássio no Brasil. Câmara dos Deputados, Consultoria Legislativa, Brasília.

Oliveira, L. A. M. de, 2008. Potássio, Sumário Mineral. Acesso em 2 de Fevereiro de 2016, disponível em Departamento Nacional de Produção Mineral: http//www.dnpm.gov.br

Oliveira, L. M., 2014. DNPM. Acesso em Fev de 2016, disponível em Departamento Nacional de Produção Mineral:

http://www.dnpm.gov.br/dnpm/sumarios/potassiosumariomineral-2014

Roest, W. R., Verhoef, J., \& Pilkington, M., 1992. Magnetic interpretation using the analytical signal. Geophysics, 57, 116-125. 